Luana Bandeira de Mello Amaral

Universidade Federal do Ceará, Fortaleza, Ceará, Brasil

Thiago Brasileiro de Vasconcelos

Universidade Federal do Ceará, Fortaleza, Ceará, Brasil

Fabiane Elpídio de Sá

Universidade Federal do Ceará, Fortaleza, Ceará, Brasil

Andrea Soares Rocha da Silva

Universidade Federal do Ceará, Fortaleza, Ceará, Brasil

Raimunda Hermelinda Maia Macena

Universidade Federal do Ceará, Fortaleza, Ceará, Brasil

\title{
Violência doméstica e a Lei Maria da Penha: perfil das agressões sofridas por mulheres abrigadas em unidade social de proteção
}

Resumo: A violência baseada no gênero tem se constituído em um fenômeno social que influencia sobremaneira o modo de viver, adoecer e morrer das mulheres. Este estudo visa conhecer as diferenças antes e após a criação da Lei Maria da Penha (LMP) nas agressões sofridas pelas mulheres que foram atendidas na Unidade de Proteção Especial do Estado do Ceará. Trata-se de um estudo seccional, exploratório-descritivo e documental. A amostra foi composta por 197 prontuários das mulheres atendidas em uma Unidade de Proteção Especial do Estado do Ceará entre os anos de 2001 e 2012. Os dados foram analisados através do SPSS $®$ versão 20. As questões éticas deste estudo foram alicerçadas na Resolução n. ${ }^{\circ}$ 466/12. 0 projeto foi aprovado pelo Comitê de Ética em Pesquisa (COMEPE) da Universidade Federal do Ceará, por meio do protocolo $n^{\circ} 369.332$. Os resultados apontam que as mulheres agredidas são jovens $(53,5 \%)$, pardas $(47,2 \%)$, sem união estável $(68,0 \%)$, com baixa escolaridade $(91,4 \%)$,

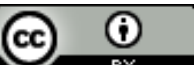

Esta obra está sob licença Creative Commons. 
sem renda mensal fixa (30,5\%), que residem em casa própria $(35,5 \%)$ com familiares $(13,7 \%)$, são beneficiárias de algum programa de transferência de renda $(26,9 \%)$ e não possuem trabalhos formais $(69,1 \%)$. Os agressores são jovens $(71,7 \%, p=0,862)$, desenvolvem trabalho manual $(41,5 \%$, $p=0,976)$, consomem álcool $(86,8 \%, p=0,814)$, drogas ilícitas $(54,7 \%, p=0,249)$ e cigarro $(54,7 \%$, $p=0,931)$. Após a implantação da $L M P$, os agressores possuem mais antecedentes criminais $(58,5 \%, p=0,000)$; a agressão tem ocorrido mais de uma vez, com maior número de denúncias e número de boletim de ocorrência, sendo o uso de substâncias psicoativas $(22,6 \%, p=0,032)$ ou ciúme $(18,9 \%, p=0,032)$ o fator desencadeante através de força física $(45,3 \%, p=0,619)$, representada em hematomas $(13,2 \%, p=0,726)$ ou não deixando marcas perceptíveis $(22,6 \%$, $p=0,726)$ localizadas na cabeça, rosto e pescoço $(28,3 \%, p=0,031)$. O perfil da violência doméstica se modificou com a promulgação da Lei Maria da Penha e este cenário demanda o desenvolvimento de ações sociais e de saúde voltadas para erradicação/controle e assistência efetiva deste grave problema social e de saúde pública.

Palavras-chave: violência doméstica; mulheres; agressão.

\section{Introdução}

A violência contra as mulheres (VCM) é considerada um problema de saúde, de direitos humanos, de segurança pública e de justiça (GRANJA; MEDRADO, 2009; DAY et al., 2003). A violência doméstica e familiar exerce grande impacto nas taxas de homicídio contra mulheres. O Brasil, num ranking de 84 países, ordenados segundo as taxas de homicídios femininos, é o $7^{\circ}$ onde mais se matam mulheres (DATASENADO, 2013). No período entre 1996 e 2006, o número total de homicídios registrados pelo Sistema de Informação de Mortalidade (SIM/DATASUS) teve um aumento de $20 \%$, sendo superior ao crescimento da população, que foi de $16,3 \%$ nesse mesmo período (WAISELFISZ, 2008). Atualmente, esta taxa chega a 33-39\% (WAISELFISZ, 2013).

A partir dos anos 90, com a efetiva participação da Organização Mundial da Saúde (OMS) nas questões de mortes femininas, o tema VCM adquiriu status internacional, posto que a violência coloca as mulheres numa situação de vulnerabilidade e de perigo, demandando políticas de proteção e apoio (HEISE, 1998; KRUG, 2002).

O Ceará é um Estado vanguardista neste segmento, tendo instaurado, desde 1992, a Casa do Caminho, unidade da Secretaria de Ação Social do Governo, de proteção especial em funcionamento no Estado, que surgiu com a necessidade de oferecer proteção e acolhimento às mulheres que denunciam a violência sofrida, oferecendo assistência jurídica e psicossocial, além da reintegração dessa população no âmbito familiar e social. O abrigo recebe mulheres em situação de risco, encaminhadas pelas Delegacias de Defesa da Mulher, que não dispõem de situação financeira para viver longe do lar ou não têm

522 Estudos Feministas, Florianópolis, 24(2): 521-540, maio-agosto/2016 
parentes ou amigos que possam acolhê-las, acompanhadas pelos filhos, onde podem permanecer acolhidas até 90 dias (PINHEIRO; FROTA, 2006). Constitui-se, muitas vezes, na única e última alternativa que possibilita o rompimento da relação conjugal.

No Brasil, com vista ao amparo das mulheres em situação de violência, foram criadas, em 1998, as unidades de proteção asseguradas pelo Programa de Prevenção, Assistência e Combate à Violência contra a Mulher, conveniado com estados, municípios e organizações não governamentais (PINHEIRO; FROTA, 2006). Mais tarde, no final de 2006, foi promulgada a Lei Maria da Penha (LMP), que qualificou a VCM como uma violação dos direitos humanos e um comportamento criminal no país (PITANGUY; HERINGER, 2002), prevendo medidas de integração operacional entre o Poder Judiciário, o Ministério Público e a Defensoria Pública com as áreas de assistência social, educação, habitação e saúde (SOUZA; KÜMPEL, 2007).

A LMP tem por intuito aumentar o rigor das punições às agressões contra as mulheres no âmbito doméstico ou familiar, possibilitando a decretação da prisão, além de aumentar as penas e outras medidas protetivas (SANTOS, 2010) e, com isso, poder contribuir para a redução da VCM no país.

Diante deste cenário, para que os profissionais da saúde consigam atuar na implantação de estratégias como forma de reduzir e prevenir os casos de violência contra as mulheres e suas consequências, é mister conhecer as diferenças - antes e após a criação da LMP - nas agressões sofridas pelas mulheres que foram atendidas na Unidade de Proteção Especial do Estado do Ceará, fazendo-se necessário esse estudo.

\section{Metodologia}

Estudo seccional, descritivo e documental realizado na Unidade de Proteção Especial à Mulher do Estado do Ceará, vinculado à Secretaria do Trabalho e Desenvolvimento Social (STDS), à Delegacia dos Direitos da Mulher e ao Conselho Cearense dos Direitos da Mulher - cognominado de Casa do Caminho.

A amostra foi composta pelos prontuários das mulheres atendidas pela Casa do Caminho que foram vítimas de qualquer tipo de violência doméstica. Para definir o tamanho da amostra, considerou-se o total de mulheres atendidas por ano e estimou-se $30 \%$ através de amostra estratificada proporcional por ano. Das 608 mulheres atendidas no período de 2001 a 2012, foram 183 prontuários para compor a amostra e considerou-se uma perda de $7 \%(n=14)$, perfazendo amostra total de 197 prontuários. Para seleção dos prontuários, 
gerou-se uma lista de números aleatórios sem repetição por meio através do Microsoft Office Excel® 2007 for Windows. Caso o prontuário não fosse encontrado ou não atendesse aos critérios de elegibilidade, era selecionado o prontuário numeralmente posterior, organizado por ordem de entrada na casa-abrigo pela própria Unidade. Foram excluídos os prontuários de mulheres menores de idade e os que não tinham informações completas ou consistentes.

Os dados foram coletados por três pesquisadores cegos (não conheciam o objetivo do estudo e nem as variáveis que seriam analisadas), previamente treinados, entre julho a dezembro de 2013, através de formulário contendo variáveis sócio-demográficas (idade, raça, religião, estado civil, escolaridade, renda familiar, participação de programas governamentais de renda, tipo de relacionamento com o agressor, número de filhos); relacionadas ao agressor (escolaridade, antecedentes criminais, motivo gerador da agressão) e relacionadas à denúncia (meios utilizados, tipo de violência vivenciada pela mulher). Sendo considerados confidenciais como propriedade conjunta das partes envolvidas, os dados pessoais ou qualquer dado que permitiam identificação foram excluídos da pesquisa (RESOLUÇÃO 466/2012).

O banco de dados foi digitado em dupla entrada no Microsoft Office Exce/ ${ }^{\circledR} 2007$, sendo as análises realizadas pelo software Statistical Package for Social Science ${ }^{\circledR}$ (SPSS) versão 20. Para análise inferencial, optou-se por fazer um recorte relativo ao período de promulgação da LMP, já que esta legislação modificou a forma de enfrentamento da violência doméstica por garantir melhor assistência às vítimas no Brasil. Realizou-se estatística inferencial para comparação entre as variáveis através do teste de qui-quadrado de Pearson segundo adoção do nível de significância de $5 \%(p<0,05)$. A normalidade dos dados foi testada por meio do teste de Kolmogorov Smirnov.

As questões éticas deste estudo foram alicerçadas na Resolução n. ${ }^{\circ} 466 / 12$. O projeto foi aprovado pelo Comitê de Ética em Pesquisa (COMEPE) da Universidade Federal do Ceará, conforme o protocolo n 369.332.

\section{Resultados}

De acordo com os dados encontrados, a maioria era jovem $(29,76 \pm 7,27$; mín. = 18- máx. = 58 anos $)$, parda $(47,2 \%)$, sem união estável $(73,0 \%)$, com baixa escolaridade $(91,4 \%$ eram alfabetizadas, $80 \%$ não concluíram o ensino fundamental), sem renda mensal fixa $(30,5 \%)$, residia em casa própria (35,5\%) com familiares ( $13,7 \%)$, era beneficiária de algum programa governamental de renda $(26,9 \%)$ e não

524 Estudos Feministas, Florianópolis, 24(2): 521-540, maio-agosto/2016 
possuía trabalhos formais no período da agressão (serviços domésticos $=37,6 \%$ ou desempregada $=31,5 \%$ ) (tabela 1 ).

Tabela 1 - Dados sócio-demográficos da população estudada

\begin{tabular}{|c|c|c|}
\hline Caracterisficas sócio-demográficas & $\mathbf{N}$ & $\%$ \\
\hline \multicolumn{3}{|l|}{ Idade } \\
\hline $15 ? \multimap 25$ anos & 66 & 33,5 \\
\hline $25 ? \longrightarrow 30$ anos & 44 & 22,3 \\
\hline Acima de 31 anos & 86 & 43,7 \\
\hline Não informado & 1 & 0,5 \\
\hline \multicolumn{3}{|l|}{ Raça } \\
\hline Branca & 42 & 21,3 \\
\hline Negra & 22 & 11,2 \\
\hline Parda & 93 & 47,2 \\
\hline Indigena & 23 & 11,7 \\
\hline Não informada & 17 & 8,6 \\
\hline \multicolumn{3}{|l|}{ Estado civil } \\
\hline Solteira & 144 & 73,0 \\
\hline Casada & $\$ 2$ & 26,4 \\
\hline Não informado & 1 & 0,5 \\
\hline \multicolumn{3}{|l|}{ Escolaridade } \\
\hline Não Alfabetizada & 12 & 6,1 \\
\hline Alfabetizada & 180 & 91,4 \\
\hline Não informada & $s$ & 2,5 \\
\hline \multicolumn{3}{|l|}{ Renda familiar } \\
\hline Sem renda & 60 & 30,5 \\
\hline Até 1 salário minimo & 54 & 27,4 \\
\hline l a 3 salários mínimos & 18 & 9,1 \\
\hline Maior que 3 salärios minimos & 1 & 0,5 \\
\hline Não informada & 64 & 32,5 \\
\hline \multicolumn{3}{|l|}{ Tipo de residência } \\
\hline Própria & 70 & 35,5 \\
\hline Cedida & 16 & 8,1 \\
\hline Alugada & 25 & 12,7 \\
\hline Invadida, mutirão e hotel & 17 & 8,6 \\
\hline Não informado & 69 & 35,0 \\
\hline Mora com familiares & 27 & 13,7 \\
\hline Participa de programas governamentais de renda & 53 & 26,9 \\
\hline \multicolumn{3}{|l|}{ Categeria profissional } \\
\hline Não trabalha/desempregada & 62 & 31,5 \\
\hline Prestaçào de serviços e comerciärias & 21 & 10,7 \\
\hline Trabalhadora de Serviços domésticos & 74 & 37,6 \\
\hline Trabalho manual " & 25 & 12,7 \\
\hline Outros & 7 & 3,5 \\
\hline Não informado & 8 & 4,1 \\
\hline
\end{tabular}

* Produção de bens e serviços industriais. 
A maior parte do atendimento às mulheres ocorreu antes da implantação da LMP $(73,0 \%)$, sendo que estiveram abrigadas por cerca de 22,76 $\pm 20,57$ dias (mín. = 1- máx. $=110$ dias). A relação com o agressor era de vinculação estável (namorado $=71,1 \%$, marido $=15,2 \%$ ) há menos de 10 anos $(72,1 \%, 193,22 \pm 29,01$ meses; mín. = 0-máx. $=$ 372). Os motivos apontados para a violência foram ciúmes $(20,3 \%)$, sendo a força física $(40,1 \%)$ o principal meio utilizado pelo agressor (tabela 2).

Foi observado que houve modificação no perfil da agredida e do agressor após a LMP. Neste caso, as agredidas são, na sua maioria, jovens $(29,83 \pm 7,25$ vs $29,55 \pm 7,39, \mathrm{p}=$ $0,718)$, solteiras $(75,5 \%$ vs $66,0 \%, p=0,551)$, alfabetizadas $(91,7 \%$ vs $90,6 \%, p=0,506)$ e com renda de até um salário mínimo $(20,1 \%$ vs $47,2 \%, p=0,001)$. As mulheres abrigadas sofreram violência na gestação $(59,0 \%$ vs $52,8 \%, p=0,583)$, tinham história de violência na família $(57,8 \%$ vs $49,1 \%, p=$ $0,346)$, sendo o tipo mais comum a violência física $(38,2 \%$ vs $34,0 \%, p=0,461)$, perpetrada pelo pai $(20,8 \%$ vs $7,5 \%, p=$ $0,043)$ e por parentes da própria família $(5,6 \%$ vs $15,1 \%, p=$ 0,043) (tabela 3).

Os agressores são, predominantemente, jovens $(35,9 \pm$ 9,81 vs $34,8 \pm 11,37, p=0,862$ ), desenvolvem trabalho manual ( $26,4 \%$ vs $41,5 \%, p=0,976$ ), consomem álcool $(61,8 \%$ vs $86,8 \%$, $\mathrm{p}=0,814)$, drogas ilícitas $(29,9 \%$ vs $54,7 \%, \mathrm{p}=0,249)$ e cigarro (30,6\% vs $54,7 \%, p=0,931)$. Apesar do incremento das prevalências das variáveis estudadas, excetuando-se os que possuíam antecedentes criminais $(8,3 \%$ vs $58,5 \%, p=0,000)$, não foram verificadas diferenças estatísticas no perfil dos agressores antes e após a LMP (tabela 3).

Foi observado um aumento considerável no percentual dos dados registrados no prontuário após a LMP em relação ao perfil da agressão. As reincidências das agressões estão presentes em todo o período estudado $(92,4 \%$ vs $94,3 \%, p=$ $0,694)$, sendo diferente, estatisticamente, o número de boletins de ocorrência (BO) referidos antes e após a LMP, com aumento para mais de três $\mathrm{BO}(-\%$ vs $11,3 \%, \mathrm{p}=0,000)$ e para o número de denúncias $(5,6 \%$ vs $1,9 \%, p=0,000)$, diminuindo 0 percentual das mulheres que ficavam omissas perante a situação de agressão sofrida. O fator desencadeante, antes da LMP, estava relacionado a ciúmes $(29,2 \%$ vs $18,9 \%, p=$ $0,032)$ ou motivo banal $(26,9 \%$ vs $37,7 \%, p=0,032)$. Após a lei, o uso de substâncias psicoativas (15,3\% vs $22,6 \%$, p = $0,032)$ prevaleceu, seguido pelo ciúme $(29,2 \%$ vs $18,9 \%, p=$ $0,032)$. Não houve diferenças estatísticas em relação ao meio de agressão, pois a força física prevaleceu em ambos os períodos $(38,2 \%$ vs $45,3 \%, p=0,619)$. Houve, porém, um aumento do uso de armas $(6,2 \%$ vs $11,3 \%, p=0,619)$. No que se refere à avaliação clínica da mulher agredida, houve

526 Estudos Feministas, Florianópolis, 24(2): 521-540, maio-agosto/2016 
Tabela 2 - Características da experiência com violência da população estudada

\begin{tabular}{|c|c|c|}
\hline Caracterisficas releciomadas à violência & $\mathbf{N}$ & $\%$ \\
\hline Anteccdentes criminais & 4 & 2,0 \\
\hline \multicolumn{3}{|l|}{ Ano da agressẫo } \\
\hline $2001-2006$ & 144 & 73,0 \\
\hline $2007-2012$ & 53 & 27,0 \\
\hline \multicolumn{3}{|l|}{ Tempo de permanência } \\
\hline $17 \multimap 30$ dias & 141 & 71,6 \\
\hline $312 \longrightarrow 060$ dias & 41 & 20,8 \\
\hline $61 ?-0.90$ dias & 10 & 5,1 \\
\hline $917 \rightarrow 120$ dias & 3 & 1,5 \\
\hline Nầ informado & 2 & 1,0 \\
\hline \multicolumn{3}{|l|}{ Relacionamento com e agressor } \\
\hline Marido & 30 & 15,2 \\
\hline Namorado & 140 & 71,1 \\
\hline Ex-thamorado & 19 & 9,6 \\
\hline Ourros & 5 & 2,5 \\
\hline Nâo informado & 3 & 1,5 \\
\hline \multicolumn{3}{|l|}{ Tempo de relacionamente } \\
\hline $0 ? \longrightarrow 120$ meses & 142 & 72,1 \\
\hline $121 ? \rightarrow 240$ meses & 36 & 18,2 \\
\hline $241 ? \longrightarrow 360$ meses & 4 & 2,0 \\
\hline $361 ? \longrightarrow 480$ meses & 1 & 0,5 \\
\hline \multicolumn{3}{|l|}{ Fater descncadeante } \\
\hline Substâncias pricoativas & 34 & 17,3 \\
\hline Cinimes & 40 & 20,3 \\
\hline Sem motivo'motivo banal & 37 & 18,8 \\
\hline Finankeiro/patrimonial & 12 & 6,1 \\
\hline Traiçalo & 8 & 4,1 \\
\hline Nio sceita separaçà & 17 & 8,6 \\
\hline Relaç̇o scxual forcada & 7 & 3,6 \\
\hline Filhosiparemes & 23 & 11,7 \\
\hline Fez denúncia & 4 & 2,0 \\
\hline Ciámes/Substaincia psicoativa & 11 & 5,6 \\
\hline Nlo informado & 4 & 2,0 \\
\hline \multicolumn{3}{|l|}{ Meios utilinados } \\
\hline Força fisica & 79 & 40,1 \\
\hline Ammas & 15 & 7,6 \\
\hline Verbal & 31 & 15,7 \\
\hline Força tîsica e verbal & 19 & 9,6 \\
\hline Força fisica c amuas & 22 & 11,2 \\
\hline Verbal e arma branca & 4 & 2,0 \\
\hline Outros & 5 & 2,5 \\
\hline Nio houve agressẫo & 1 & 0,5 \\
\hline Nło informado & 21. & 10,7 \\
\hline
\end{tabular}


Tabela 3 - Dados relacionados ao perfil da agredida e do agressor antes e depois da criação da Lei nº 11.340

\begin{tabular}{|c|c|c|c|c|c|}
\hline \multirow{3}{*}{ Caractertstices } & \multicolumn{4}{|c|}{ Ane da Agroscio } & \\
\hline & \multirow{2}{*}{\multicolumn{2}{|c|}{$2001-2006$}} & \multicolumn{2}{|c|}{$2007-2012$} & \\
\hline & & & & $\%$ & \\
\hline \multicolumn{5}{|l|}{ Agrofitifo } & $\mathbf{p}^{\prime}$ \\
\hline Idade & & & & & 0,100 \\
\hline $15 ?=025$ anos & 49 & 34,0 & 17 & 32.1 & \\
\hline $25 ? \rightarrow 30$ anos & 30 & 208 & 14 & 26,4 & \\
\hline Acima de 31 anos & 65 & 45,1 & 21 & 39,6 & \\
\hline Nov informado & . & . & 1 & 1,9 & \\
\hline Estado chill & & & & & 0.551 \\
\hline Solieina & 109 & 75,5 & 35 & 66,0 & \\
\hline Casada & 34 & 23,6 & 18 & 34,0 & \\
\hline Nbo informabo & 1 & 0,7 & - & - & \\
\hline Escolaridade & & & & & 0,506 \\
\hline N3o Alfabetizada & 9 & 6.2 & 3 & 5,7 & \\
\hline Alsabetizads & 132 & 91.7 & 48 & 90,6 & \\
\hline Noo informada & 3 & 2,1 & 2 & 3.8 & \\
\hline Renda famaliar & & & & & $0,601=$ \\
\hline Sem renala & 48 & 33,3 & 12 & 22,6 & \\
\hline Até I salärio minimo & 29 & 20,1 & 25 & 47,2 & \\
\hline I a 3 salirios minimos & 9 & 6,2 & 9 & 17,0 & \\
\hline Maiof que 3 salarios minimes & : & & 1 & 1,9 & \\
\hline Nos informads & 58 & 40,3 & 6 & 11,3 & \\
\hline Viskència gestaçio & & & & & 0.583 \\
\hline $\operatorname{Sim}$ & 85 & 590 & 28 & 52,8 & \\
\hline Nso & 37 & 25,7 & 15 & 28,3 & \\
\hline Nào informala & 22 & 153 & 10 & 18.9 & \\
\hline História de violinncia na familia & & & & & 0.346 \\
\hline Sim & 83 & 57,6 & 26 & 49,1 & \\
\hline Nao & 39 & 27,1 & 8 & 15,1 & \\
\hline Não infonmada & 22 & 15,3 & 19 & 35,8 & \\
\hline Autor de violéncia familiar & & & & & $0,043^{*}$ \\
\hline Pai & 30 & 208 & 4 & 7,5 & \\
\hline Pai, padrosto & iI & 76 & 2 & 3,8 & \\
\hline Compunbeiro & 8 & 56 & 3 & 5,7 & \\
\hline Panthles do maricb & 18 & 12.5 & 7 & 13,2 & \\
\hline Paremes da peipecia familia & 8 & 5,6 & 8 & 15,1 & \\
\hline Ontros & 9 & 6,2 & 3 & 5,7 & \\
\hline Nào informaso & 60 & 41.7 & 26 & 49,1 & \\
\hline Tipo de vintiscia na familia & & & & & 0,461 \\
\hline Fisica & 55 & 38,2 & 18 & 34,0 & \\
\hline Vertal & 1 & 0,7 & 1 & 1.9 & \\
\hline Abuso sexual & 10 & 6,9 & 8 & 15,1 & \\
\hline Mais de um tipo & 2 & 1.4 & . & 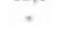 & \\
\hline Näo informado & 76 & 528 & 26 & 49,1 & \\
\hline \multicolumn{6}{|l|}{ Agressar } \\
\hline Idade & & & & & 0.862 \\
\hline $207 \multimap 40$ anos & 76 & 528 & 38 & $\pi 1,7$ & \\
\hline $41 ? \rightarrow 00$ anos & 27 & 188 & 10 & 18,9 & \\
\hline 617 - 80 and & 2 & 1.4 & 2 & 3,8 & \\
\hline Nö infommado & 39 & 27,1 & 3 & 5,7 & \\
\hline Categoria profosbaaal & & & & & 0.976 \\
\hline Nao iratulha/desentongada & 27 & 188 & 10 & 18,9 & \\
\hline Prestaçbo de senviges e comerciarios & 53 & 36,8 & 6 & 11,3 & \\
\hline Trabaltho manual (produçâo de bers e scrvipos & 38 & 26,4 & 22 & 41,5 & \\
\hline indestriaisis) & & & & & \\
\hline Outmos & 19 & 13,2 & 13 & 24,5 & \\
\hline Näo informada & 7 & 4.9 & 2 & 3,8 & \\
\hline Informa uso de ailcoel & & & & & 0.814 \\
\hline $\operatorname{Sim}$ & 89 & 61,8 & 46 & 86,8 & \\
\hline Naso & 12 & 8.3 & 7 & 13,2 & \\
\hline Näo informado & 43 & 29.9 & - & - & \\
\hline \multicolumn{6}{|l|}{ Informa use de Drogas ilicitas } \\
\hline Sim & 43 & 29,9 & 29 & 54,7 & 0.249 \\
\hline Na & 47 & 32,6 & 21 & 39,6 & \\
\hline No infornado & 54 & 37,5 & 3 & 5,7 & \\
\hline Informa Tabagismons & & & & & 0.931 \\
\hline Sim & 44 & 30,6 & 29 & 54,7 & \\
\hline No & 36 & 25,0 & 23 & 43,4 & \\
\hline Nào infommado & 64 & 44,4 & 1 & 1,9 & \\
\hline Powsi antreedentes criminais & & & & & $0,600^{*}$ \\
\hline Sim & 12 & 8.3 & 31 & 58,5 & \\
\hline $\mathrm{NaO}$ & 130 & 903 & 18 & 34,0 & \\
\hline Nise infonuado & 2 & 1.4 & 4 & 7.5 & \\
\hline
\end{tabular}

'Valor de $p<0,05$; teste Qui-quadrado de Pearson.

528 Estudos Feministas, Florianópolis, 24(2): 521-540, maio-agosto/2016 
'Psicológica, moral, física e sexual. diminuição do número de exames não informados $(77,8 \%$ vs $50,9 \%$ ), sendo que aumentou o número de lesões que não deixam marcas perceptíveis ( $12,5 \%$ vs $22,6 \%, p=0,706)$ ou hemorragias $(4,2 \%$ vs $13,2 \%, p=0,726)$. As lesões corporais localizadas na cabeça, rosto e pescoço $(31,2 \%$ vs $28,3 \%$, p $=0,031$ ) e a associação de diferentes tipos de violência $(59,7 \%$ vs $56,6, p=0,011)$ continuaram sendo prevalentes após a LMP (tabela 4).

\section{Discussão}

Não ocorreram mudanças significativas no perfil das mulheres vítimas de agressão acolhidas em unidades de proteção no Estado do Ceará, antes e após a promulgação da LMP. Os agressores, depois da promulgação da lei em questão, possuem mais antecedentes criminais e envolvimento com drogas ilícitas. Houve modificação dos fatores desencadeadores da violência - de ciúme ou motivos banais para uso de substâncias psicoativas ou ciúme - com qualificação (agravamento) da violência pelo uso de armas, sendo as lesões predominantes os hematomas localizados na face e no tronco superior.

De modo geral, o perfil de violência no Brasil centrase na violência física como mais frequente entre mulheres, seguida pela violência moral e a psicológica, diferente dos achados neste estudo. A violência sexual, apesar de ser uma das menos mencionadas nessa pesquisa, teve um crescimento acentuado no último ano (DATASENADO, 2013). O presente trabalho, assemelhando-se a outros estudos, revela que a violência perpetrada tem diversas expressões, sendo a associação dos diferentes tipos de violência' mais prevalente depois da LMP (COSTA et al., 2011; MATTOS, RIBEIRO, CAMARGO, 2012; BASILE, HERTZ, BACK, 2007). Costa et al. (201 1) e Mattos, Ribeiro e Camargo (2012) identificaram em seus estudos que, em poucos casos, apenas um tipo de violência foi relatado como forma de agressão, sendo a violência perpetrada contra mulher a associação da física e da psicológica.

Embora encontradas diferenças entre os vários tipos de violência, observamos que elas se entrelaçam de diferentes maneiras. Schraiber et al. (2007b) defendem que a violência mais grave está associada à sobreposição de diversas formas de violência, onde a associação da psicológica, física e sexual constitui as situações extremamente graves (ALMEIDA; PASA; SCHEFFER, 2009).

Os dados demonstram que a promulgação da LMP repercutiu no modo de denunciar das mulheres agredidas, gerando um histórico de recorrência das denúncias. No Brasil, houve um aumento do número de denúncias de violências 
Tabela 4 - Dados relacionados ao perfil da agressão antes e depois da criação da Lei no 11.340

\begin{tabular}{|c|c|c|c|c|c|}
\hline \multirow{3}{*}{ Canucteristicas } & \multicolumn{4}{|c|}{ Ane da Agressão } & \multirow{3}{*}{$P^{\prime}$} \\
\hline & \multicolumn{2}{|c|}{$2001-2006$} & \multicolumn{2}{|c|}{$2007-2012$} & \\
\hline & $\mathrm{N}$ & $\%$ & $\mathrm{~N}$ & $\%$ & \\
\hline Primeira vez & & & & & 0,694 \\
\hline Sim & 6 & 4,2 & 3 & 5,7 & \\
\hline Nầ & 133 & 92,4 & 50 & 94,3 & \\
\hline Nâo informado & 5 & 3,5 & - & - & \\
\hline Números de boletim de ocorrência & & & & & $0,000^{*}$ \\
\hline Nenhum & 8 & 5,6 & 1 & 1,9 & \\
\hline $1 ? \multimap 2$ & 134 & 93,1 & 44 & 83,1 & \\
\hline-3 & - & * & 6 & 11,3 & \\
\hline Nào informado & 2 & 1,4 & 2 & 3,8 & \\
\hline Fator desencadeante & & & & & $0.032^{*}$ \\
\hline Substincia psicoativas & 22 & 15,3 & 12 & 22,6 & \\
\hline Ciúmes & 42 & 29,2 & 10 & 18,9 & \\
\hline Sem motiva'motivo banal & 38 & 26,4 & 9 & 37,7 & \\
\hline Traiçào & 4 & 2.8 & 4 & 7,5 & \\
\hline Relação sexual forçada & 4 & 2,8 & 3 & 5,7 & \\
\hline Filhos/parentes & 20 & 13,9 & 3 & 5,7 & \\
\hline Ciùmes/substância psicoativa & 11 & 7,6 & . & . & \\
\hline Não informado & 3 & 2,1 & 1 & 1,9 & \\
\hline Meios utilizados & & & & & 0,619 \\
\hline Força física & 55 & 38,2 & 24 & 45,3 & \\
\hline Armas & 9 & 6,2 & 6 & 11,3 & \\
\hline Verbal & 22 & 15,3 & 9 & 17,0 & \\
\hline Força física e verbal & 17 & 11,8 & 2 & 3,8 & \\
\hline Força fisica e armas & 14 & 9,7 & 8 & 15,1 & \\
\hline Verbal e arma branca & 3 & 2,1 & 1 & 1,9 & \\
\hline Outros & 3 & 2,1 & 2 & 3.8 & \\
\hline Nవ̃o houve agressão & 1 & $\overrightarrow{0}, 7$ & . & . & \\
\hline N3o informado & 20 & 13,9 & 1 & 1.9 & \\
\hline Tipo de violència & & & & & $0,011^{*}$ \\
\hline Moral & $s$ & 3,5 & . & . & \\
\hline Psicológica & 10 & 6,9 & 2 & 3,8 & \\
\hline Fisica & 21 & 14,6 & 9 & 17,0 & \\
\hline Psicológica, moral, fisica & 86 & 59,7 & 30 & 56,6 & \\
\hline Fisica, sexual & 19 & 13,2 & 7 & 132 & \\
\hline Tentativa & 1 & 0,7 & - & - & \\
\hline Todas & - & . & 5 & 9,4 & \\
\hline NGo informado & 2 & 1,4 & - & - & \\
\hline Exame Fisico & & & & & 0,726 \\
\hline Sem leșio & 18 & 12.5 & 12 & 22.6 & \\
\hline Hemorragia & 6 & 4,2 & 7 & 13,2 & \\
\hline Cortes & 3 & 2,1 & 3 & 5,7 & \\
\hline Cicntrixes & - & - & 1 & 1,9 & \\
\hline Múltiplas & 4 & 2,8 & 3 & 5,7 & \\
\hline Queimaduras & 1 & 0,7 & - & 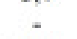 & \\
\hline Nho informado & 112 & 77,8 & 27 & 50,9 & \\
\hline Local da lesão & & & & & $0,031^{*}$ \\
\hline Cabeça'rosto/ pescoço & 45 & 31,2 & 15 & 28,3 & \\
\hline Corpo todo & 23 & 16,0 & 10 & 19.9 & \\
\hline Região genital & 1 & 0,7 & 4 & 7,5 & \\
\hline Tronco & 1 & 0,7 & 4 & 7,5 & \\
\hline Cabeça/tronco & 4 & 2,8 & 1 & 1,9 & \\
\hline Cabecs/membros & 16 & $\overrightarrow{11}, 1$ & 5 & 9,4 & \\
\hline Sem lesào & 5 & 3,5 & 1 & 1,9 & \\
\hline Nso informado & 49 & 34,0 & 13 & 24,5 & \\
\hline
\end{tabular}

'Valor de $p<0,05$; teste Qui-quadrado de Pearson.

530 Estudos Feministas, Florianópolis, 24(2): 521-540, maio-agosto/2016 
sofridas por mulheres logo após a primeira agressão, entre 2009 e 2013. No mesmo período, apenas um pequeno percentual de mulheres oficializou denúncia formal contra os agressores em delegacias comuns ou especializadas ou na Central de Atendimento à Mulher mais tardiamente terceira vez em diante (DATASENADO, 2013). Para Kronbauer e Meneghel (2005), isso ocorre devido ao fenômeno chamado "ciclo da violência", representado por fases que evoluem de acordo com o grau da agressão. Inicialmente se trata de desentendimentos, humilhações, provocações mútuas, seguidas pelo uso de estratégias de ameaças, finalizando o conflito em agressão física, que leva à denúncia (DAY et al., 2003; BRANDÃO, 2006; MELO et al., 2009).

O perfil das mulheres agredidas no Ceará se mantém estável ao longo dos anos (COSTA et al., 2011 ; MATTOS, RIBEIRO, CAMARGO, 2012; PINHEIRO, 2012) e assemelha-se a outros no país, excetuando-se o estado civil, sendo estas vítimas de violência cometidas pelo seu companheiro, com aumento do número de denúncias e, consequentemente, boletins de ocorrência, prevalecendo a associação de diferentes tipos de violência (física, sexual, psicológica e moral) (SCHRAIBER et al., 2002; ADEODATO et al., 2005; BRANDÃO, 2006; VALE et al., 2013). Os dados referentes à cor da pele/raça e à escolaridade são escassos, sendo prevalente a notificação da cor parda e o nível de escolaridade alfabetizada. Destacamos que essas variáveis merecem atenção no preenchimento da ficha de notificação de violência, haja vista seu potencial para auxiliar na mensuração das desigualdades sociais e sua associação com a ocorrência da violência (SILVA et al., 2013).

A motivação para a violência contra mulheres não apresenta diferenças regionais. Tanto em Florianópolis (SC) como no Ceará, o ciúme, o fato de o homem ser contrariado, a ingestão de álcool e a suspeita de traição são fatores apontados pelas vítimas (DEEKE et al., 2009; ACOSTA, GOMES, BARLEM, 2013). O consumo em larga escala de substâncias alcoólicas entre homens, seu uso naturalizado e associado à cultura (DEEKE et al., 2009; ALMEIDA, PASA, SCHEFFER, 2009),

${ }^{2}$ Relações sociais desiguais de poder entre homens e mulheres que são o resultado de uma construção social do papel do homem e da mulher a partir das diferenças sexuais. aliado às fortes questões de gênero ${ }^{2}$ nas relações violentas, parece justificar esta motivação (REICHENHEIM; DIAS; MORAES, 2006).

As diferentes formas de manifestação de violência contra as mulheres parecem estar associadas ao álcool e às drogas ilícitas. No Rio Grande do Sul, Vieira et al. (2014) observaram que o uso abusivo de álcool e de drogas, por parte dos companheiros, potencializou a violência vivida, o sofrimento relatado e a submissão das mulheres. Assim sendo, embora a associação entre a violência e uso, abuso e dependência de substâncias represente um agravante nos 
episódios de violência doméstica e venha sendo investigada, sua relação causal ainda não pode ser inferida (DAY et al., 2003; ALMEIDA, PASA, SCHEFFER, 2009; FONSECA et al., 2009). Desse modo, as mulheres agredidas no Ceará, como em outros locais, são duplamente vulneráveis, pois, se, por um lado, sofrem múltiplas violências, por outro lado seus agressores têm consumo acrescido de álcool e drogas (ALMEIDA; PASA; SCHEFFER, 2009).

Outro aspecto investigado foi o aumento e o agravamento dos antecedentes criminais dos agressores, uma vez que a LMP determina a agressão como punitiva, autorizando a justiça a decretar prisão preventiva caso ocorram riscos físicos ou psicológicos à mulher (AMICO, 2007). Assim, essa mistura (violências múltiplas e de repetição associada ao uso de álcool) torna as violências mais presentes nas relações de afeto e denuncia uma assimetria nas relações de poder e gênero, tornando a violência vivida mais grave com consequências mais danosas às vítimas (DEEKE et al., 2009; BRANDÃO, 2014).

As mulheres abrigadas trazem marcas de violência vivida por meio da força física, muitas vezes estampada em hematomas e, outras vezes, invisíveis e imperceptíveis a olho nu, passando despercebidas pela equipe profissional da Casa do Caminho. Muitos estudos retratam diferentes tipos de instrumentos e lesões (DAY et al., 2003). Ferreira (2010) observou, em Fortaleza-CE, que a força corporal como meio de agressão esteve presente na maioria dos casos de violência doméstica, seguida de ameaça e de objeto pérfurocortante. Garcia et al. (2008), em Uberlândia-MG, detectaram que a maioria das lesões perceptíveis era decorrente de agentes mecânicos e que os óbitos decorreram de ferimentos por arma branca e por arma de fogo. Blay (2003), ao investigar a violência doméstica e os vários tipos de homicídio contra as mulheres em São Paulo, afirma que qualquer instrumento serve para agressão, entre eles, faca, ácido, madeira, ferro, além das próprias mãos, mas detectou que, em sete de cada dez casos, o revólver é o mais usado (ILHA; LEAL; SOARES, 2010). No Ceará como em São Paulo (GARBIN et al., 2006) e no Rio Grande do Sul (PAZ, 2013), a face e o crânio são os alvos preferidos dos agressores. Tal fato pode ser explicado por duas vertentes. A primeira pauta-se no entendimento de que a região da cabeça está mais exposta e menos protegida. A segunda vertente, mais psicológica, estruturase sobre o preceito de que a face e o crânio refletem o centro das atenções no ser humano, sendo um atributo muito valorizado socialmente, que é a beleza feminina (SCHRAIBER et al., 2002; SILVA; AQUINO, 2008; DAY et al., 2003). O agressor encontra, na face da vítima, a maneira mais fácil de atingir a sua honra, uma vez que procura tornar visível a lesão, the

532 Estudos Feministas, Florianópolis, 24(2): 521-540, maio-agosto/2016 
causando situação vexatória perante os demais (SCHRAIBER et al., 2002).

Embora haja predominância da face e pescoço, as outras áreas do corpo que apresentam lesões refletem o comportamento defensivo por parte da vítima que tenta proteger a face dos golpes, usando esses membros como anteparo (DESLANDES, GOMES, SILVA, 2000; SCHRAIBER et al., 2002; ILHA, LEAL, SOARES et al., 2010). Portanto, qualquer que seja a explicação para o padrão de lesões estabelecidas, sabe-se que, quando não identificadas e tratadas adequadamente, essas alterações levam a graves sequelas funcionais, estéticas e psicossociais (ARAÚJO et al., 2011; FIGUEREDO et al., 2012).

Destarte, apesar da LMP, a subnotificação de violência ainda é elevada no Brasil, ocorrendo a denúncia somente quando as lesões se tornam mais graves, colocando em risco a vida das mulheres (DAY et al., 2003; DIAS, 2007). Este fato parece estar associado a diversos fatores de vulnerabilidade pessoal e social (SILVA, VARGENS, 2009; BRANDÃO, 2006), tais como: medo do agressor (DATASENADO, 2013); baixo nível de conhecimento sobre direitos ou por descrença no sistema jurídico (na polícia e na Justiça) (DIAS, 2007); falta de condições econômicas para viver sem o companheiro; a preocupação com os filhos e o medo de estarem sujeitas a reações mais violentas pela parte agressora ao se verem denunciadas (BRASIL, 2010; BENFICA, VAZ, DUTRA, 2007).

Como limitações deste estudo, podemos citar as relacionadas ao desenho transversal, que não permite o estabelecimento de relações de causa e efeito, as mudanças nas fichas de avaliação ao longo dos anos, a incompletude dos dados e a inexistência de profissionais de saúde na Unidade de Proteção Especial do Estado do Ceará como parte da equipe multiprofissional, sendo composta apenas por psicólogos e assistentes sociais. Entretanto, registros localizados puderam ser completados com a utilização dos documentos complementares existentes nos prontuários (boletim de ocorrência, ficha de atendimento em emergência em decorrência de agressões), auxiliando a visibilizar e a combater a banalização desse tipo de violência.

Apesar das limitações, os dados estudados permitem advertir que o atendimento em uma Unidade de Atenção a Mulheres Vítimas de Violência não pode consistir no único instrumento de combate à violência ou de assistência a essas mulheres, tendo em vista que há a necessidade da interação de outros serviços (saúde, polícia e órgãos de assistência jurídica) para a promoção integral e recuperação da vítima. Além disso, precisamos reconhecer que a LMP contribuiu para quebrar a cadeia de violência contra as mulheres dentro de muitas famílias, porém, o que dita a legislação nem sempre se traduz inteiramente na prática cotidiana dos 
serviços públicos e privados de saúde e de assistência social. Há, ainda, a necessidade de investimento e formação de profissionais que atuem em espaços sociais especiais para essas mulheres, para que os mesmos estejam aptos à estruturação da rede de serviços de proteção a elas, incluindo a linha de cuidados integrais à saúde.

Partindo do fato de que a violência afeta significativamente o processo saúde-doença das mulheres, podemos considerar a Fisioterapia, área de atuação e formação dos autores do estudo, como profissão apta para identificar, assistir e referir as mulheres vitimizadas, competindo-lhe atuar nas múltiplas lesões associadas, principalmente, à violência física e/ou sexual que resultam em alterações musculoesqueléticas e posturais no corpo e nas condições crônicas de violência doméstica, que dizem respeito aos agravos que as mulheres desenvolvem em decorrência da violência repetida e recorrente em suas vidas. Assim sendo, a inclusão de outros profissionais de saúde (equipe multidisciplinar), além de psicólogos e assistentes sociais, nas Unidades de Proteção, propiciará a identificação de outros problemas de saúde que demandam atendimento diferenciado através da orientação e intervenções transdisciplinares.

\section{Conclusão}

A violência contra as mulheres é um fenômeno complexo, polissêmico e controverso. Apesar das políticas de proteção e apoio à mulher para diminuição da violência, esta ainda apresenta números elevados e atinge mulheres em diferentes contextos de vulnerabilidade.

As mudanças ocorridas no perfil das mulheres vítimas de agressão acolhidas em unidades de proteção no Estado do Ceará, antes e após a promulgação da LMP, não sofreram mudanças significativas. Os agressores possuem mais antecedentes criminais e envolvimento com drogas ilícitas. Os fatores desencadeantes da violência eram centrados, principalmente, por ciúme ou motivos banais; após a LMP, foram alterados para uso de substâncias psicoativas ou ciúme, com qualificação (agravamento) da violência pelo uso de armas, sendo as lesões mais prevalentes os hematomas localizados na face e no tronco superior. Este estudo nos permitiu observar que o perfil das agressões sofridas pelas mulheres vítimas de violência doméstica se modificou com a promulgação da LMP, sendo que esta proporcionou um avanço na percepção do fenômeno da violência contra a mulher na sociedade, provocando uma redução do número de mulheres atendidas nos abrigos de proteção.

Deste modo, muito ainda há que se realizar no sentido de prevenir a violência contra a mulher. As ações de prevenção devem ser agregadas a políticas sociais e educacionais

534 Estudos Feministas, Florianópolis, 24(2): 521-540, maio-agosto/2016 
visando à redução das disparidades de gênero. Por outro lado, a realização de novas investigações da violência contra a mulher abre possibilidades para uma prevenção mais eficaz. Acredita-se que conhecer o perfil da violência doméstica, antes e a após a Lei Maria da Penha, possibilita o desenvolvimento de ações sociais e de saúde voltadas para erradicação do problema.

\section{Referências}

ACOSTA, D. F.; GOMES, V. L. de O.; BARLEM, E. L. D. "Profile of police reports related to violence against women". Acta paul. enferm., São Paulo, v. 26, n. 6, 2013. Disponível em: $<$ http://www.scielo.br/scielo.php?script=sci_arttext\&pid= S0103-21002013000600007 > . Acesso em: 20 set. 2014.

ADEODATO, V. G. et al. "Qualidade de vida e depressão em mulheres vítimas de seus parceiros". Revista de Saúde Pública, v. 39, n. 1, 2005, p. 108-113. Disponível em: <http:/ /www.scielo.br/scielo.php?pid=\$0034-89102005000100 014\&script=sci_arttext > . Acesso em: 15 ago. 2014.

ALMEIDA, R. M. M. de; PASA, G. G.; SCHEFFER, M. "Álcool e violência em homens e mulheres". Psicol. Reflex. Crit, Porto Alegre, v. 22, n. 2, 2009. Disponível em: <http:// www.scielo.br/scielo.php?script $=$ sci_arttext\&pid $=$ S010279722009000200012 >. Acesso em: 20 set. 2014.

AMICO, C. C. "Violência doméstica e familiar contra a mulher: necessidade de representação da vítima em caso de lesão corporal leve e culposa". Boletim IBCCRIM, ano 14, n. 170, janeiro, 2007. Disponível em: <http://www.compro missoeatitude.org.br/wp-content/uploads/2014/02/ Boletim-170 Amico.pdf>. Acesso em: 22 mar. 2014.

ARAÚJO, R. J. G. et al. "Análise dos traumas de face que acometem mulheres vítimas de violência doméstica". Full Dent. Sci, v. 3, n. 9, 2011, p. 78-85. Disponível em: <www.research gate.net/...of.../02bfe510dd13b1d17c000000>. Acesso em: 2 set. 2014.

BASILE, K. C.; HERTZ, M. F.; BACK, S. E. Intimate partner violence and sexual violence victimization assessment instruments for use in healthcare setting. Atlanta: Centers for Disease Control and Prevention, 2007. Disponível em: <http://www. cdc.gov/ncipc/pub-res/images/ipvandsvscreening.pdf $>$. Acesso em: 15 ago. 2014.

BENFICA, F. S.; VAZ, M.; DUTRA, D. "A violência doméstica praticada contra mulheres: revisão dos aspectos médicoslegais e jurídicos". Revista IOB de Direito Penal e Processual Penal, Porto Alegre, n. 42, fev./mar, 2007, p. 24-40. Disponível em: <http://www.lexml.gov.br/urn/urn:lex:br:rede. virtual.bibliotecas:artigo.revista:2007;100079341 > . Acesso em: 20 set. 2014. 
BLAY, E. A. "Violência contra a mulher e políticas públicas". Estudos Avançados, v. 17, n. 49, 2003, p. 87-98. Disponívelem: $<$ http://www.scielo.br/scielo.php?script=sci_arttext\&pid $=$ SO 103-40142003000300006>. Acesso em: 15 ago. 2014.

BRASIL. Resolução CNS n466, de 12 de dezembro de 2012. Aprova diretrizes e normas regulamentadoras de pesquisa envolvendo seres humanos. Diário Oficial da União. Brasilia, 2012. Disponível em: <http://conselho.saude.gov.br/ resolucoes/2012/Reso466.pdf > . Acesso em: 10 ago. 2014. Presidência da República. Secretaria de Políticas Públicas para as Mulheres. Relatório Anual do Observatório Brasil de Igualdade de Gênero 2009/2010. Brasília: Secretaria de Políticas Públicas para as Mulheres, 2010. Disponível em: <http://www.mulheres.gov.br/maismulheres-no poder/desigualdadesentremulheresehomens/ politica/relatorio_anual_2009_10.pdf >. Acesso em: 10 ago. 2014.

BRANDÃO, E. R. "Renunciantes de direitos? A problemática do enfrentamento público da violência contra a mulher: o caso da delegacia da mulher". Physis, Rio de Janeiro, v. 16, n. 2, 2006. Disponível em: <http://www.scielo.br/df/ physis/v16n2/v16n2a05.pdf >. Acesso em: 20 set. 2014.

COSTA, A. M. et al. "Violência contra a mulher: caracterização de casos atendidos em um centro estadual de referência". Revista Rene, Fortaleza, 2011 . Disponível em: <http://www.revistarene.ufc.br/revista/index.php/revista/ article/viewFile/1 123/pdf > . Acesso em: 20 set. 2014.

DATASENADO. Violência Doméstica e Familiar contra a Mulher. Secretaria de Transparência, 2013. Disponível em: <http:// www.senado.gov.br/senado/datasenado/pdf/datasena do/DataSenado-Pesquisa-Violencia_Domestica_contra a_Mulher_2013.pdf > . Acesso em: $2 \overline{0}$ set. 2014.

DAY, V. P. et al. "Violência doméstica e suas diferentes manifestações". Revista de Psiquiatria Rio Grande do Sul, 2003. Disponível em: <http://www.scielo.br/pdf/rprs/v25s1/ a03v25s1 >. Acesso em: 15 ago. 2014.

DEEKE, L. P. et al. "A dinâmica da violência doméstica: uma análise a partir dos discursos da mulher agredida e de seu parceiro". Saúde e Sociedade, v. 18, n. 2, p. 248258, 2009. Disponível em: <http://www.scielo.br/cielo.php? pid $=$ S0 $10412902009000200008 \&$ script $=$ sci_arttext $>$. Acesso em: 20 set. 2014.

DESLANDES, S. F.; GOMES, R.; SILVA, C. M. F. P. da. "Caracterização dos casos de violência doméstica contra a mulher atendidos em dois hospitais públicos do Rio de Janeiro". Cad. Saúde Pública, Rio de Janeiro, v. 16, n. 1, 2000. Disponível em: <http://www.scielo.br/scielo.php?script= sci_arttext\&pid=S0102-311X2000000100013 > . Acesso em: 24 out. 2014.

536 Estudos Feministas, Florianópolis, 24(2): 521-540, maio-agosto/2016 
DIAS, M. B. "A Lei Maria da Penha na justiça: a efetividade da Lei 11.340/2006 de combate à violência doméstica e familiar contra a mulher". Revista dos Tribunais, São Paulo, 2007. Disponível em: <http://www.ambito-juridico. com.br/site/?n_link=revista_artigos_leitura\&artigo_id $=$ $11065 \&$ revista caderno $=3 \overline{>}$. Acesso em: 10 out. $20 \overline{1} 14$.

FERREIRA, R. C. Análise da violência contra a mulher a partir da vigilância realizada por serviços sentinela em Fortaleza, Ceará. Dissertação (Mestrado em Saúde Coletiva), Universidade de Fortaleza, Fortaleza, Ceará, 2010. 75f. Disponível em: <http://uol01.unifor.br/oul/ conteudosite/F1066343724/Dissertacao.pdf > . Acesso em: 4 set. 2014.

FIGUEREDO, M. C. et al. "Prevalência de mulheres vítimas de violência no município de Porto Alegre e a influência de suas variáveis no âmbito odontológico". RFO, Passo Fundo, v. 17, n. 3, 2012, p. 254-260. Disponível em: <http:// files.bvs.br/upload/S/1413-4012/2012/v17n3/a3701.pdf>. Acesso em: 4 set. 2014.

FONSECA, A. M. et al. "Padrões de violência domiciliar associada ao uso de álcool no Brasil". Revista de Saúde Pública, v. 43, n. 5, 2009, p. 743-749. Disponível em: <http:// www.scielo.br/pdf/rsp/v43n5/24.pdf > . Acesso em: 18 ago. 2014.

GARBIN et al. "Violência doméstica: análise das lesões em mulheres". Cadernos de Saúde Pública, v. 22, n. 12, 2006 , p. 67-73. Disponível em: <http://www.scielo.br/scielo.php? pid=S0102-31 1X2006001200007\&script=sci_arttext $>$. Acesso em: 18 ago. 2014

GARCIA, M. V. et al. "Caracterização dos casos de violência contra a mulher atendidos em três serviços na cidade de Uberlândia, Minas Gerais, Brasil”. Cadernos de Saúde Pública. Rio de Janeiro, v. 24, n. 11, 2008, p. 2551-2563. Disponível em: <http://www.scielo.br/scielo.php?pid=SO $102311 \times 2008001100010 \&$ script=sci_abstract\&tlng $=p t>$. Acesso em: 3 set. 2014.

GRANJA, E.; MEDRADO, B. "Homens, violência de gênero e atenção integral em saúde". Rev. Psicologia e Sociedade, v. 21, n. 1, 2009, p. 25-34". Disponível em: $<$ http://www.scielo.br/pdf/psoc/v21n1/04.pdf > . Acesso em: 4 ago. 2014.

HEISE, L. L. "Violence against women: an integrated framework". Violence against women, v. 4, n. 1, 1998, p. 262-290. Disponível em: <http://vaw.sagepub.com/content/4/3/ 262.short>. Acesso em: 13 set. 2014.

ILHA, M. M.; LEAL, S. M. C.; SOARES, J. S. F. "Mulheres internadas por agressão em um hospital de Porto Seguro: (in)visibilidade da violência". Ver. Gaúcha Enferm., Porto Alegre (RS), v. 31, n. 2, 2010, p. 328-34. Disponível em: <http:// 
www.scielo.br/scielo.php?pid=S1983-144720100002000 18\&script $=$ sci arttext $>$. Acesso em: 13 set. 2014.

KRONBAUER, J. F. D.; MENEGHEL, S. N. Perfil da violência de gênero perpetrada por companheiro. Revista de Saúde Pública, São Paulo, v. 39, n. 5, 2005, p. 695-701. Disponível em: <http://www.scielosp.org/pdf/rsp/v39n5/26287.pdf > . Acesso em: 18 ago. 2014.

KRUG, E. G. World report on violence and health. Genebra: World Health Organization, 2002. Disponível em: <http:// whqlibdoc. who.int/hq/2002/9241545615.pdf > . Acesso em: 20 out. 2014

MATTOS, P. R.; RIBEIRO, I. da S.; CAMARGO, V. C. "Análise dos casos notificados de violência contra mulher". Cogitare enfermagem, Curitiba, v. 17, n. 4, 2012. Disponível em: <http://ojs.c3sl.ufpr.br/ojs/index.php/cogitare/article/ viewFile/30383/19659>. Acesso em: 8 out. 2014.

MELO, Z. M. et al. "Violência intrafamiliar: crime contra a mulher na área metropolitana do Recife". Psicol Estud, Maringa, v. 14, n. 1, 2009, p. 111 . Disponível em: <http://ww.scielo.br/ scielo.php?pid =S1413-73722009000100014\&script= sci_arttext>. Acesso em: 8 out. 2014.

PAZ, P. de O. Violência física e homicídios em mulheres rurais: vulnerabilidades de gênero e iniquidades sociais. Dissertação (Mestrado), Programa de Pós-Graduação em Enfermagem, Escola de Enfermagem da Universidade Federal do Rio Grande do Sul, Porto Alegre, 2013. Disponível em: <http://www.lume.ufrgs.br/handle/10183/ 75979 > . Acesso em: 10 out. 2014.

PINHEIRO, M. J. M.; FROTA, M. H. P. "As casas-abrigo: política pública de proteção à mulher vítima de violência doméstica". O público e o privado, n. 8, 2006, p. 109-130. Disponível em: <http://seer.uece.br/?journal=opublico eoprivado\&page $=$ article\&op $=$ view $\&$ path []$=171>$. Acesso em: 7 jul. 2014.

PINHEIRO, M. J. M. Mulheres abrigadas: violência conjugal e trajetórias de vida. Fortaleza: UECE; EDMETA, 2012.

PITANGUY, J.; HERINGER, R. “Diálogo regional da América Latina e Caribe sobre direitos reprodutivos e violência contra a mulher: papéis e responsabilidade de homens jovens e adultos". Cidadania, Estudo, Pesquisa, Informação e Ação. Rio de Janeiro, 2002. Disponível em: <http://www.cepia.org. br/doc/vawportuguese.pdf>. Acesso em: 7 jul. 2014.

REICHENHEIM, M. E.; DIAS, A. S.; MORAES, C. L. Co-ocorrência de violência física conjugal e contra filhos em serviços de saúde. Revista de Saúde Pública, São Paulo, v. 40, n. 4, 2006, p. 595-603. Disponível em: <http://www.scielo.br/ scielo.php?script =sci_arttext\&pid = s003489102006000500007 >. Acesso em: 5 set. 2014.

538 Estudos Feministas, Florianópolis, 24(2): 521-540, maio-agosto/2016 
SANTOS, S. M. "Da delegacia da mulher à Lei Maria da Penha: absorção/tradução de demandas feministas pelo Estado". Revista Crítica de Ciências Sociais, n. 89, 2010, p. 15370. Disponível em: <http://www.ces.uc.pt/ficheiros2/files/ gender\%20workshopRCCS_89_Cecilia_Santos.pdf $>$. Acesso em: 5 set. 2014.

SCHRAIBER, L. B. et al. "Violência contra a mulher: estudo em uma unidade de atenção primária à saúde". Revista de Saúde Pública, v. 36, n. 4, 2002, p. 470-477. Disponível em: <http://www.scielo.br/scielo.php?pid=S003489102002000400013 \&script $=$ sci arttext $>$. Acesso em: 10 set. 2014.

"Prevalência da violência contra a mulher por parceiro íntimo em regiões do Brasil". Revista Saúde Pública, v. 41, n. 5, p. 797-807, 2007a. Disponível em: $<$ http://www.scielo.br/scielo.php?script=sci_arttext\&pid= S0034-89102007000500014 > Acesso em: 5 set. 2014.

"Violência contra mulheres entre usuárias de serviços públicos de saúde da Grande São Paulo". Revista Saúde Pública, v. 41, n. 3, 2007b, p. 359-67. Disponível em: $<$ http://www.scielo.br/scielo.php?pid=s0034$89102007000300006 \&$ script $=$ sci_arttext $>$. Acesso em: 5 set. 2014.

SILVA, C.; VARGENS, O. M. da C. "A percepção de mulheres quanto à vulnerabilidade feminina para contrair DST/HIV". Rev. Esc. Enferm., São Paulo, v. 43, n. 2, 2009. Disponível em: <http://www.scielo.br/scielo.php?pid=\$008062342 $009000200020 \&$ script $=$ sci_arttext $>$.Acesso em: 20 out. 2014.

SILVA, I. V.; AQUINO, E. M. "Padrão de distúrbios psíquicos menores em mulheres vítimas de violência atendidas em uma unidade de urgência e emergência". Cad. Saúde Pública, v. 24, n. 9, 2008, p. 2103-2114. Disponível em: $<$ http://www.scielo.br/pdf/csp/v24n9/16.pdf> . Acesso em: 10 set. 2014.

SILVA, M. C. M. et al. "Characterization of cases of physical, psychological and sexual violence and negligence reported in Recife, Pernambuco". Epidemiol. Serv. Saúde, v. 22, n. 3 , 2013. Disponível em: <http://scielo.iec.pa.gov.br/ scielo. php?pid $=$ S1679-49742013000300005\&script $=$ sci abstract>. Acesso em: 15 set. 2014.

SOUZ̄A, L. A.; KÜMPEL, V. F. Violência doméstica e familiar contra a mulher: Lei 11.340/2006. São Paulo: Método, 2007. Disponível em: <http://biblioteca2.senado.gov.br:8991/F/ func $=$ itemglobal\&doc_library $=S E N 01 \& d o c \_n u m b e r=00$ 0781328 >. Acesso em: 10 set. 2014.

VALE, S. L. L. et al. "Repercussões psicoemocionais da violência doméstica: perfil de mulheres na atenção básica". Revista Rene, 2013. Disponível em: <http:// 
www.revistarene.ufc.br/revista/index.php/revista/article/ viewFile/1 123/pdf > . Acesso em: 15 ago. 2014.

VIEIRA, L. B. et al. "Abuso de álcool e drogas e violência contra as mulheres: denúncias de vividos". Revista brasileira de enfermagem, v. 67, n. 3, 2014, p. 366-372. Disponível em: $<$ http://www.scielo.br/pdf/reben/v67n3/0034-7167-reben67-03-0366.pdf > . Acesso em: 15 ago. 2014.

WAISELFISZ, J. J. Mapa da violência dos municípios brasileiros. Brasília: Ministério da Saúde, 2008. 60p. Disponível em: <http://www.mapadaviolencia.org.br/publicacoes/ Mapa 2008 municipios.pdf > . Acesso em: 10 out. 2014.

. Mapa da violência 2013. Homicídio e Juventude no Brasil. Brasília: Ministério da Saúde, 2013. 100p. Disponível em: <http://www.mapadaviolencia.org.br/pdf2013/ mapa2013 homicidios juventude.pdf $>$. Acesso em: 10 out. 2014.

[Recebido em 05/1 1/2015 e

aceito para publicação em 09/12/2015]

Domestic Violence and the Maria da Penha Law: Profile of Aggression in Women Sheltered in a Social Unit of Protection

Abstract: The violence based on gender has been constituted as a social phenomenon which influences the way of life, illness and death of women. This study analyzes the profile of assaults suffered by women victims of domestic violence before and after the creation of the Maria da Penha Law (LMP). It is a cross-sectional, descriptive exploratory search through archival study. The sample consisted of 197 medical records of women who were attended at a Special Protection Unit of the state of Ceará in the years between 2001 and 2012. Data were analyzed using SPSS version 20. The ethical issues of this study were based on Resolution $n .{ }^{\circ} 466 / 12$. The project was approved by the Federal University of Ceará Research Ethics Committee (COMEPE) protocol 369.332. The results show that battered women are young (53.5\%), brown (47.2\%), without stable union (68.0\%), with low education (91.4\%), no fixed monthly income (30.5\%), reside at home (35.5\%) with family members (13.7\%), are beneficiaries of any program income transfer $(26.9 \%)$ and do not have formal jobs (69.1\%). The attackers are young (71.7\%, $p=0.862$ ), develop manual work (41.4\%, $p=0.976)$, consume alcohol (86.8\%, $p=0.814)$, illicit drugs $(54.7 \%, p=0.249)$ and tobacco $(54.7 \%, p=0.931)$. After the implementation of $L M P$, the attackers have more criminal history (58.7\%, $p=0.000$ ); aggression has occurred more than once, with the largest number of complaints and the number of police occurrence report, and the use of psychoactive substances (22.6\%, $p=0.032$ ) or jealousy (18.9\%, $p=0.032)$ triggering factors through physical $(45.3 \%, p=0.619)$ force represented in leaving $(13.2 \%, p=0.726)$ no noticeable bruises $(22.6 \%, p=0.726)$ or marks located on the head, face and neck (28.3\%, $p=0.031)$. The profile of domestic violence has changed with the enactment of Law Maria da Penha and this scenario requires the development of social and health actions aimed at eradication / control, and effective assistance of this serious social problem and public health.

Keywords: Domestic Violence; Women; Aggression.

540 Estudos Feministas, Florianópolis, 24(2): 521-540, maio-agosto/2016 